\title{
Histopathology effects of nickel nanoparticles on lungs, liver, and spleen tissues in male mice
}

\author{
Marziyeh Ajdari · Marziyeh Ziaee Ghahnavieh
}

Received: 23 November 2013/Accepted: 21 June 2014/Published online: 17 September 2014

(C) The Author(s) 2014. This article is published with open access at Springerlink.com

\begin{abstract}
Because of the classification of the nickel compounds as carcinogenic substances, there is a need for in vivo tests to nickel nanoparticles (NiNPs) for observing their effects on health experimentally. Spherical NiNPs with $10 \mathrm{~nm}$ in diameter and $75 \mathrm{ppm}$ concentration were applied for investigating their toxicities within male albino mice as an in vivo model. We randomly made sham group, control group, and $75 \mathrm{ppm}$ group (with five animals in each group). Then, the nanoparticles were injected into mice intraperitonealy for 7 days and after that their lungs, liver, and spleen were removed for histopathological observations. At the end of the test, section microscopic observations of liver, spleen, and lung in sham and control groups showed normal tissues but these tissues underwent significant abnormal effects in 75 ppm group. NiNPs can cause undesirable effects in lungs, liver, and spleen tissues with same condition of this study.
\end{abstract}

Keywords Nickel nanoparticles $\cdot$ Mice $\cdot$ Lung $\cdot$ Liver . Spleen

\section{Introduction}

The production of highly functional materials by utilizing diverse properties of nanoparticles has already begun;

\footnotetext{
M. Ajdari

Young Researchers and Elite Club, Khorasgan Branch, Islamic

Azad University, Isfahan, Iran

e-mail: ajdari-ma1365@yahoo.com

M. Ziaee Ghahnavieh $(\bowtie)$

Department of Biology, Payame Noor University, Tehran, Iran e-mail: ziaee13@gmail.com
}

however, the effects of them on humans have not been elucidated [1]. Absorbed nanoparticles by binding to proteins of plasma can enter the cells and penetrate into organs such as lung, stomach, brain, liver, kidney, heart, and testicles [2]. If these particles are toxic, defense mechanisms by reactive oxygen species (ROS) generation will result in injuries to tissues [3-5].

Liver is the first target for absorbed materials from gastrointestinal tract before becoming systemic [6]. Interference with the antioxidants takes place in the liver and spleen. Spleen as an organ that is part of the immune system can be a storage site for lymphocytes for immunity and defense against infection and filtering the blood.

The lungs because of their high blood supply and their ability to concentrate toxins are mainly susceptible to xenobiotics.

Still recent studies were not well suited to demonstrating effects of nickel nanoparticles on tissues that surely depend on exposure way, duration of treatment, dose, and nanoparticle features. So in this study, we attempted to investigate toxic effects of spherical nickel nanoparticles with special dose and by injecting method on mice during 1 week.

\section{Materials and methods}

Preparing of NiNPs

NiNPs colloid solution with diameter of $10 \mathrm{~nm}$ and concentration of $100 \mathrm{ppm}$ was purchased from Notrino.Co of Tehran and then size and shape of them were controlled by transmission electron microscopy (TEM). After that, required dose was prepared $(75 \mathrm{ppm})$ by diluting with distilled water. 
Experimental animals and their treatment

Fifteen male albino strain mice with 8 week old and $24 \mathrm{~g}$ average weight were purchased from Isfahan University and were randomly group housed (sham group, control group, 75 ppm group) in standard caging with sawdust bedding, environmental enrichment with free access to sterile water and food in pathogen-free and standard condition with National Institutes of Health guidelines for the human use of laboratory animals. The animals were maintained on a normal $12 \mathrm{~h}$ light and dark cycle, at a temperature of $25-27{ }^{\circ} \mathrm{C}$, relative humidity of $10 \pm 60 \%$ and were allowed 7 days to acclimatize prior to study commencement. 5 animals in sham group were fed just with normal food and water without any injection, 5 mice in control group were injected with $0.3 \mathrm{ml} /$ day distilled water intraperitonealy, and 5 mice in 75 ppm group were injected with $0.3 \mathrm{ml} /$ day NiNPs intraperitonealy for 1 week.

Sample collection

Following the last treatment, all animals were anesthetized by intraperitoneal injection of ketamine and for histological examinations, after cutting abdomen and removing lungs, liver, and spleen tissues from each mouse, fresh portions of the lateral lobes of them were cut rapidly into $2 \mu \mathrm{m}$-thick sections. They were fixed in neutral buffered formalin (10\%), and then dehydrated with grades of ethanol (70, 80, 90, 95 and $100 \%)$. Dehydration was then followed by clearing the samples in two changes of xylene. Samples were then impregnated with two changes of molten paraffin wax, then embedded and blocked out. Paraffin sections were stained with hematoxylin and eosin (H\&E). They were monitored under light microscope and the photomicrographs of them were obtained.

\section{Statistical analysis}

All data were stored in SPSS (version 19). Group comparisons were done using the Student's $t$ test (for comparing weights) and analysis of variance (ANOVA) test with Dunnett post-test (for comparing tissues of treated groups vs. control group). All data were expressed as mean \pm standard error of mean (SEM). $P$ values less than 0.05 were considered to be significant.

\section{Results}

\section{Control of NiNps}

The morphology and size of the purchased NiNPs were controlled using transmission electron microscopy CM10 Philips (TEM). The images clearly show that the average size of the

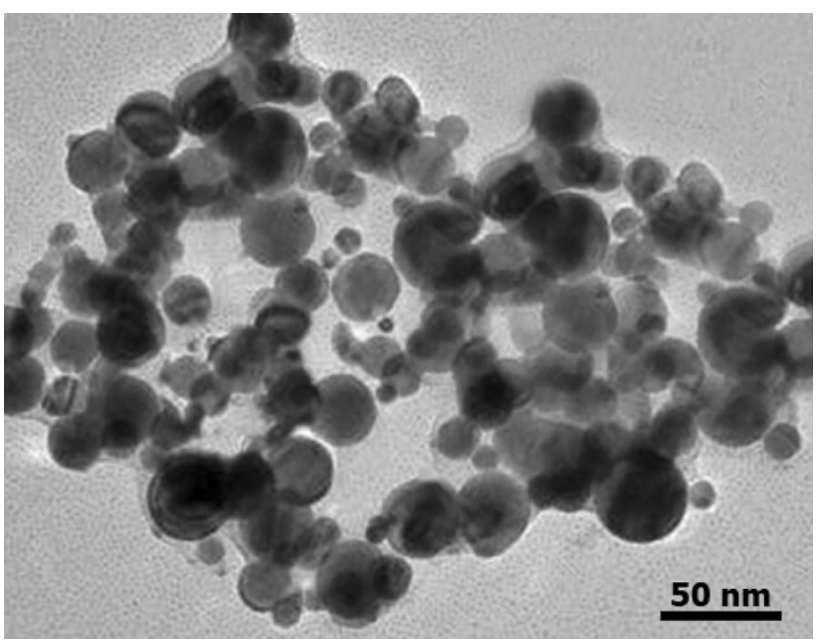

Fig. 1 Image of NiNPs by TEM

particles was found to be in the order of $10 \mathrm{~nm}$ and they were relatively uniform in diameter with spherical shape (Fig. 1). TEM consisted of a long column with source of electron rays on top that after transmitting through the specimen, electron rays hit a photographic film or screen, built of fluorescent materials, and create an image. Since some rays do not pass through the sample, black spots are left on the image and therefore electron microscope images are black and white.

\section{Animals' body weight and appearance}

The body weight alterations of male mice before and after the treatment of NiNPs show non-significant differences $(p>0.05)$. Appearance of animals during the treatment was normal. Furthermore, no mortality was observed during the test.

\section{Liver tissue}

The image of liver tissue sections of mice in sham and control group including hepatocytes, nuclei, hepatic cords, hexagon lobules, sinusoids, central veins, and portal veins were normal. But microscopic images of liver in $75 \mathrm{ppm}$ group in comparison with sham group showed significant changes like hyperemia and expansions of central veins. Also, secretions of inflammatory cells including neutrophils and lymphocytes and increasing bile ductules were shown in portal veins. Heptocytes were hyperchromia relatively. Kupffer cells were swelled. Also dispersed apoptosis was seen (Fig. 2; Table 1).

Spleen tissue

Structure of spleen tissue in sham and control groups was natural but microscopic images of 75 ppm group versus 
Fig. 2 Histopathology effects of NiNPs on liver (a sham group, $\mathbf{b}$ control group, c 75 ppm group), spleen (d sham group, e control group, f 75 ppm group), and lung (g sham group, h control group, i 75 ppm group) in mice by injecting method, $\mathrm{H} \& \mathrm{E}$ staining, magnification $400 \times$
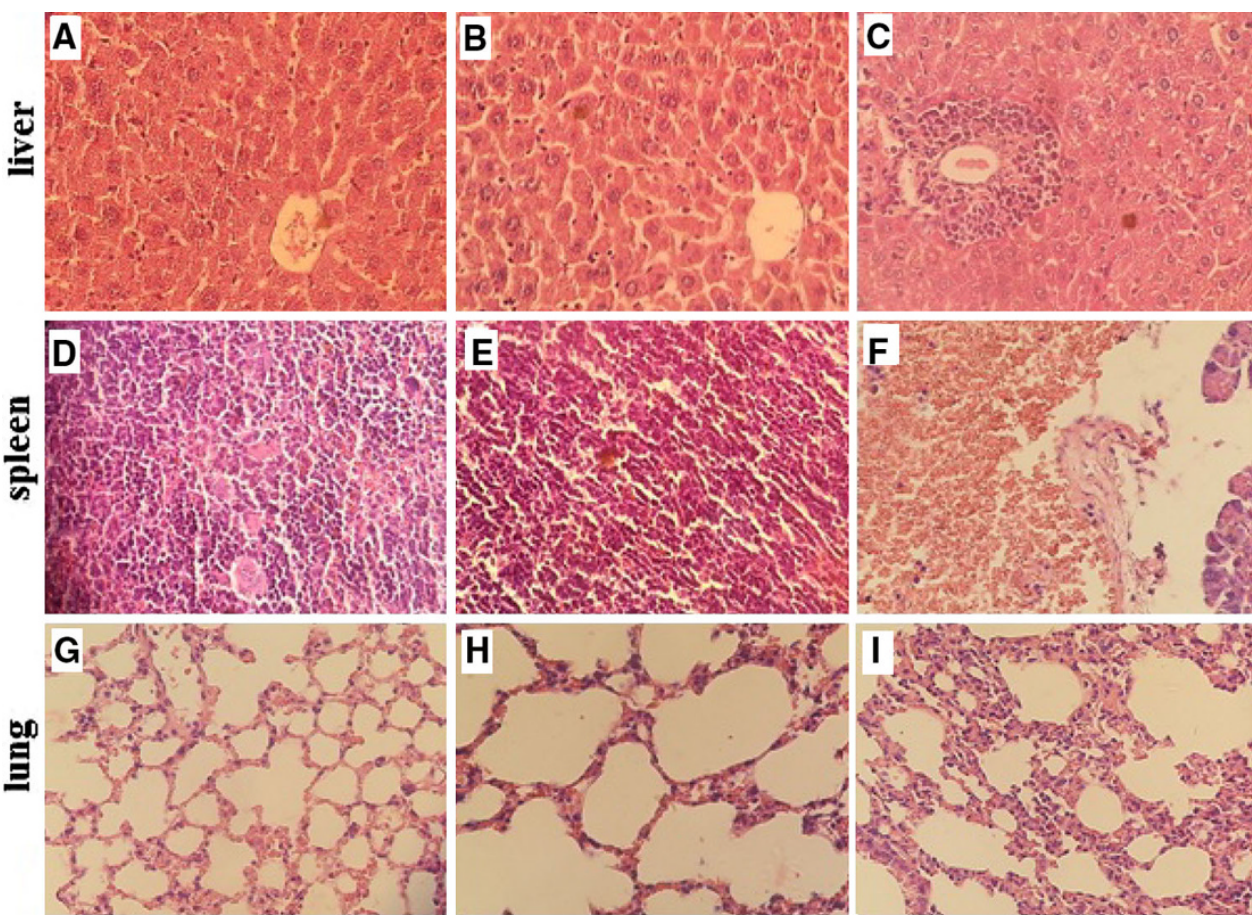

Table 1 Comparing injury grades of tissues in treated groups vs. tissues of sham group

\begin{tabular}{lllll}
\hline Groups & Number & Degregation & Mean \pm SEM & $p$ value \\
\hline Sham & 5 & Liver & $0.0 \pm 0.0$ & 1.000 \\
& & Spleen & $0.0 \pm 0.0$ & 1.000 \\
& & Lung & $0.0 \pm 0.0$ & 1.000 \\
Control & 5 & Liver & $0.0 \pm 0.0$ & 1.000 \\
& & Spleen & $0.0 \pm 0.0$ & 1.000 \\
& & Lung & $0.0 \pm 0.0$ & 1.000 \\
75 ppm & 5 & Liver & $1.6 \pm 0.5$ & $0.004^{*} *$ \\
& & Spleen & $1.0 \pm 0.4$ & $0.033^{*}$ \\
& & Lung & $0.8 \pm 0.4$ & $0.041^{*}$ \\
\hline
\end{tabular}

$*$ and ** indicate significant difference $p<0.01$ and $p<0.001$, respectively, vs. sham group

these groups showed some significant differences including sharp augmentation of number of macrophages and intense congestion of red pulp. Also in this group, sinusoids had been widened (Fig. 2; Table 1).

\section{Lung tissue}

Lung tissue sections in the sham and control groups showed normal bronchiolar epithelium and goblet cells but histological alterations in the group that daily were receiving $0.3 \mathrm{ml}$ of NiNPs intraperitonealy for one week in comparison with previous groups showed significant differences; for example some alveoli had became small and increase of interstitial fibrosis together with plenty excretion of lymphocytic exudates among intra alveoli area was showed. By the way any sign of peribronchiolite or perivasculitis was not seen (Fig. 2; Table 1).

\section{Discussion}

In many researches skin penetration of nickel particles resulting in nickel allergy or inhalation of nickel particles there by producing lung injury or inflammation have been reported [7-11] and now in this study, we tried to investigate effects of intraperitoneal injection of NiNPs on three key tissues. Most studies confirmed that administrated nanoparticles are primarily taken up by liver and spleen in a large quantity and by lung, kidney, heart, and brain in small amounts after single administration [12]. Furthermore, some nanoparticles by producing reactive oxygen species and inducing oxidative stress cause organ injuries $[13,14]$, so careful assessment of undesired effects of them in the body is important. Obtained results of histopatologic investigations in present study also emphasized those results of researches and showed low to high abnormalities in liver, spleen, and lung tissues in treated mice by NiNPs because liver and spleen act as filters for blood and by metabolizing of xenobiotics with several reactions and their vulnerabilities cause fewer damages to the body.

In the present study, lung tissue was also affected by NiNPs even though they were administrated intraperitonealy and this shows NiNPs through circulation have reached to lung organ and caused adverse biological 
reactions. Some other data have confirmed a correlation between airborne nanoparticles derived from the combustion of fossil fuel like nickel particles and cardiovascular diseases [15]. Nickel oxide is a nickel compound with extremely poor solubility that is considered to have high biopersistence in the lung [16]. Poland et al. [17] also studied intraperitoneal injection and aspiration effects of nickel nanowire with diameter of $200 \mathrm{~nm}$ and length of more than $20 \mu \mathrm{m}$ in mice and found out that they caused strong inflammation in mouse peritoneal cavity and lung, respectively, in a dose-dependent manner, so they confirmed their hazard potential. Also, the study results of Magaye et al. [18] 14 days after intravenous injection of $2 \mathrm{ml}$ of Ni nanoparticles (with diameter of $50 \mathrm{~nm}$ and three doses 1,10 and $20 \mathrm{mg} / \mathrm{kg}$ ) in rats indicate acute toxicity of NiNPs because they induced liver and spleen injury, lung inflammation, and cardiac toxicity.

\section{Conclusion}

Administrating NiNPs with the same condition of this study could cause disorder on liver, spleen and lung tissues of mice; so they can have hazard potential for human health. Of course these results need more research and application of a gradient of NiNPs doses to find toxic and safe doses for using $\mathrm{Ni}$ nanoparticles or $\mathrm{Ni}$ compounds, for example, in nanomedicine is necessary.

Open Access This article is distributed under the terms of the Creative Commons Attribution License which permits any use, distribution, and reproduction in any medium, provided the original author(s) and the source are credited.

\section{References}

1. Ogami, A., Morimoto, Y., Murakami, M., Myojo, T., Oyabu, T., Tanaka, I.: Biological effects of nano-nickel in rat lungs after administration by inhalation and by intratracheal instillation. J. Phys. Conf. Ser. 151, 012032 (2009)

2. Vaidyanathan, R., Kalishwaralal, K., Gopalram, S., Gurunathan, S.: Nanosilver-The burgeoning therapeutic molecule and its green synthesis. Biotechnol. Adv. 27(6), 924-937 (2009)

3. Abdelhalim, M.A., Jarrar, B.M.: Histological alterations in the liver of rats induced by different gold nanoparticle sizes, doses and exposure duration. J. Nanobiotechnol. 10, 5 (2012). doi:10. 1186/1477-3155-105

4. Lipka, J., Semmler-Behnke, M., Sperling, R.A., Wenk, A., Takenaka, S., Schleh, C., et al.: Biodistribution of PEG-modified gold nanoparticles following intratracheal instillation and intravenous injection. Biomaterials 31, 6574-6581 (2010)
5. Cho, W.S., Cho, M., Jeong, J., Choi, M., Han, B.S., Shin, H.S., et al.: Size-dependent tissue kinetics of PEG-coated gold nanoparticles. Toxicol. Appl. Pharmacol. 245, 116-123 (2010)

6. Akradi, L., Sohrabi Haghdoost, I., Djeddi Ali, N., Mortazavi, P.: Histopathologic and apoptotic effect of nanosilver in liver of broiler chickens. Afr. J. Biotechnol. 11(22), 6207-6211 (2012)

7. Jacob, S.E., Moennich, J.N., McKean, B.A., Zirwas, M.J., Taylor, J.S.: Nickel allergy in the United States: a public health issue in need of a "nickel directive". J. Am. Acad. Dermatol. 60(6), 1067-1069 (2009). doi:10.1016/j.jaad.2008.11.893. (Epub 2009 Jan 23. PubMed PMID: 19167779)

8. Marks Jr, J.G., Belsito, D.V., DeLeo, V.A., Fowler Jr, J.F., Fransway, A.F., Maibach, H.I., Mathias, C.G., Pratt, M.D., Rietschel, R.L., Sherertz, E.F., Storrs, F.J., Taylor, J.S.: North American Contact Dermatitis Group patch-test results, 1996-1998. Arch. Dermatol. 136(2), 272-273 (2000). (PubMed PMID: 10677115)

9. Vemula, P.K., Anderson, R.R., Karp, J.M.: Nanoparticles reduce nickel allergy by capturing metal ions. Nat. Nanotechnol. 6(5), 291-295 (2011). doi:10.1038/nnano.2011.37. (Epub 2011 Apr 3. PubMed PMID: 21460828)

10. Zhang, Q., Kusaka, Y., Zhu, X., Sato, K., Mo, Y., Kluz, T., Donaldson, K.: Comparative toxicity of standard nickel and ultrafine nickel in lung after intratracheal instillation. J. Occup. Health 45(1), 23-30 (2003). (PubMed PMID: 14605425)

11. Zhang, Q., Kusaka, Y., Sato, K., Nakakuki, K., Kohyama, N., Donaldson, K.: Differences in the extent of inflammation caused by intratracheal exposure to three ultrafine metals: role of free radicals. J. Toxicol. Environ. Health A. 53(6), 423-438 (1998). (PubMed PMID: 9537280)

12. Hillyer, J.F., Albrecht, R.M.: Gastrointestinal persorption and tissue distribution of differently sized colloidal gold nanoparticles. J. Pharm. Sci. 90(12), 1927-1936 (2001). (PubMed PMID: 11745751)

13. Antolovich, M., Prenzler, P.D., Patsalides, E., McDonald, S., Robards, K.: Methods for testing antioxidant activity. Analyst 127(1), 183-198 (2002). (Review. Erratum in: Analyst 2002 Mar;127(3):430. PubMed PMID: 11827390)

14. Baynes, J.W.: Role of oxidative stress in development of complications in diabetes. Diabetes 40(4), 405-412 (1991). (Review. PubMed PMID: 2010041)

15. Brunekreef, B., Forsberg, B.: Epidemiological evidence of effects of coarse airborne particles on health. Eur. Respir. J. 26, 309-318 (2005)

16. NTP Toxicology and Carcinogenesis Studies of Nickel Oxide (CAS No. 1313-99-1) in F344 Rats and B6C3F1 Mice (Inhalation Studies) (1996)

17. Poland, C.A., Byrne, F., Cho, W.S., Prina-Mello, A., Murphy, F.A., Davies, G.L., Coey, J.M., Gounko, Y., Duffin, R., Volkov, Y., Donaldson, K.: Length-dependent pathogenic effects of nickel nanowires in the lungs and the peritoneal cavity. Nanotoxicology 6, 899-911 (2012). doi:10.3109/17435390.2011.626535. (Epub 2011 Oct 24. PubMed PMID: 22023084)

18. Magaye, R.R., Yue, X., Zou, B., Shi, H., Yu, H., Liu, K., Lin, X., $\mathrm{Xu}$, J., Yang, C., Wu, A., Zhao, J.: Acute toxicity of nickel nanoparticles in rats after intravenous injection. Int. J. Nanomed. 9, 1393-1402 (2014). doi:10.2147/IJN.S56212. (eCollection 2014. PubMed PMID: 24648736; PubMed Central PMCID: PMC3958504) 